\title{
Incidence of Meckel's diverticulum in 100 cadavers
}

\author{
M. S. ROJHAN \\ M.D.
}

\author{
R. HEJAZI \\ M.D.
}

\section{Department of Anatomy, School of Medicine, Tehran University, Iran}

\section{Summary}

The literature concerning the embryology, histology, clinical significance and preoperative diagnosis of Meckel's diverticulum has been reviewed.

Meckel's diverticulum was found in about $6 \%$ of subjects from the Tehran region, suggesting that it occurs more frequently in Iran than previously supposed.

\section{Introduction}

Meckel's diverticulum is the most significant diverticulum occurring in the jejunum or ileum. It is a remnant of an omphalomesenteric or vitelline duct which normally obliterates at about the seventh week of foetal life (Oppenheimer, 1962). For reasons unknown, a remnant of the duct may persist, more or less completely, as a tube or cord arising usually from the ileum $25-90 \mathrm{~cm}$ from the ileocaecal valve with or without a distal attachment to the umbilicus (Fig. 1) (Gurd, 1966; Oppenheimer, 1962). It may cause volvulus, strangulation or intussusception (Soderlund, 1959).

The incidence of Meckel's diverticulum has been reported as being $2 \%$, occurring more frequently in men than in women (Martin, 1955; Oppenheimer, 1962; Soderlund, 1959). However, according to a recent study performed in the Departments of Anatomy and Pathology of Tehran University Medical School, the occurrence of Meckel's diverticulum seems to be three times greater than previously reported. The present paper reviews these findings.

\section{Materials and methods}

Eighty male cadavers were recently examined for presence of Meckel's diverticulum at Dissection Hall of Tehran University Medical School. The small intestine, from the ileocaecal valve to the ligament of Treitz was carefully examined and five cases of Meckel's diverticulum were discovered (the clinical history of these cadavers was not available).

Twenty autopsy cases (twelve male, eight female) were examined in the Autopsy Hall of Pahlavi Medical Centre, University of Tehran, and one case of Meckel's diverticulum was found.

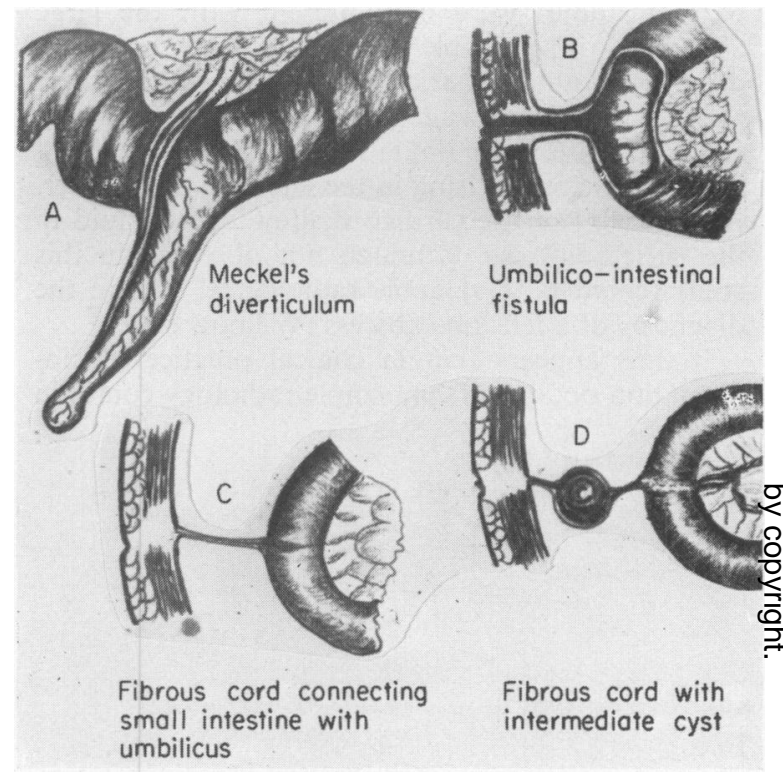

FIG. 1. Diagrams showing embryological development of Meckel's diverticulum: (A) Meckel's diverticulum ending as a blind pocket; (B) diverticulum with open connection at the umbilicus; (C) diverticulum connected to umbilicus by a fibrous cord; (D) diverticulum connected to umbilicus by a fibrous cord with intermediate cyst.

\section{Results}

In 100 cadavers examined (ninety-two male, eight female) six cases of Meckel's diverticulum were observed. The conditions of the diverticula were as follows.

\section{Case 1}

This was the cadaver of a 50-year-old man. A Meckel's diverticulum was located on the antimesenteric border of the ileum $57 \mathrm{~cm}$ from the ileocaecal valve. The diverticulum measured $3 \mathrm{~cm}$ long $\times 1.5 \mathrm{~cm}$ wide and was connected to the intestine at the base (Fig. 2). The contents of the intestine could be seen in the diverticulum. Macroscopically signs of chronic inflammation and adhesiveness were 


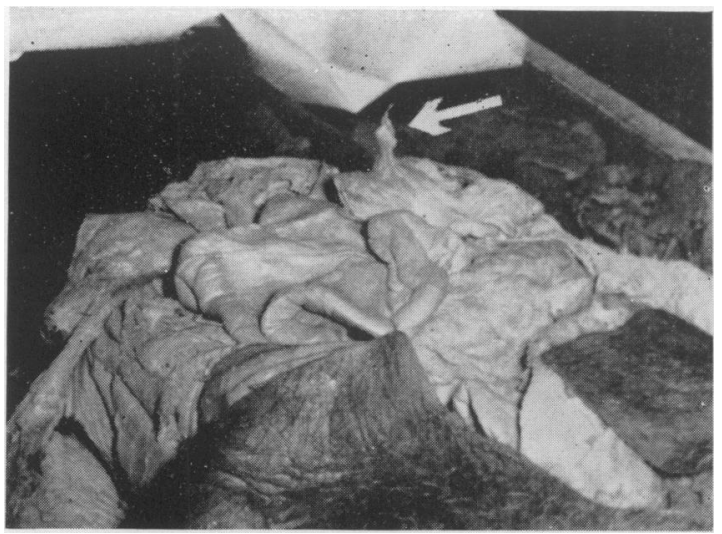

FIG. 2. (Case 1). Meckel's diverticulum as seen in the cadaver.



FIG. 3. (Case 1). Medium-power photomicrograph of Meckel's diverticulum.

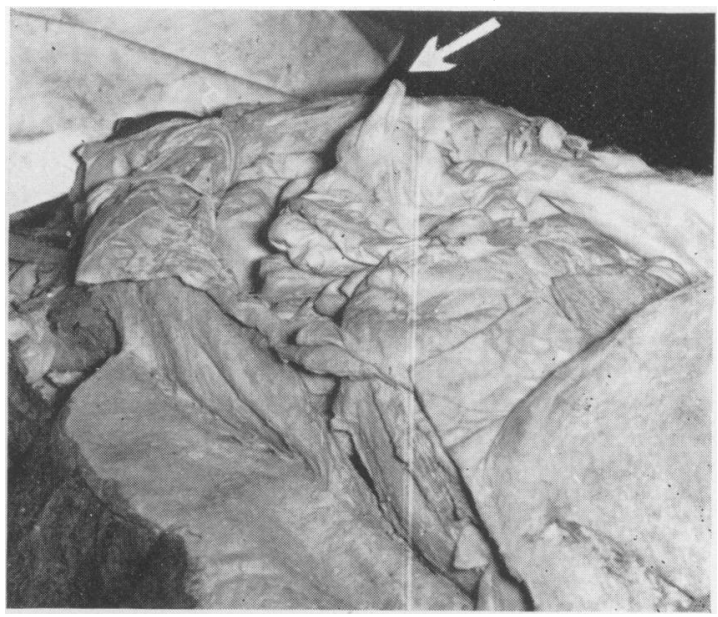

FIG. 4. (Case 2). Meckel's diverticulum on upper part of the intestine.

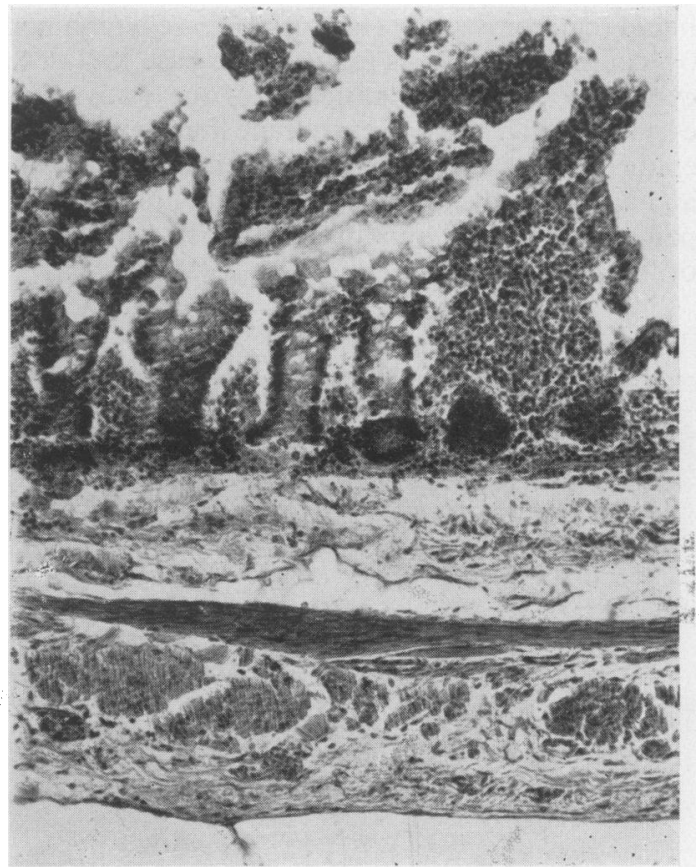

FIG. 5. (Case 2) Medium-power photomicrograph of Meckel's diverticulum resembling the small intestine (from top down: mucous membrane, submucous coat, muscular layers and serosa). 
seen. Microscopy revealed signs of subacute inflammation (Fig. 3).

\section{Case 2}

The cadaver was that of a 40 -year-old man. The Meckel's diverticulum, $4 \mathrm{~cm}$ long and $2 \mathrm{~cm}$ in diameter, was located on the anterior surface of the ileum $85 \mathrm{~cm}$ from the ileocaecal valve (Fig. 4). The diverticulum was connected to the intestine by its base and the contents of the intestine could be seen in it. The wall of the diverticulum and its serous membrane were normal macroscopically. The mucous membrane, submucosa, muscular layer and serosa were normal on microscopy (Fig. 5). The stomach, Brunner and pancreatic glands were absent.

\section{Case 3}

The body was of a man aged 45 years. A cone diverticulum with thin wall was seen on the anterior surface of the ileum, $37 \mathrm{~cm}$ from the ileocaecal valve. The diverticulum was $5 \mathrm{~cm}$ in length. The width was $3 \mathrm{~cm}$ near the intestine but it decreased toward its free end. No sign of the diverticulum entrance was found inside the intestine. The Meckel's diverticulum was thus in the form of a cyst with a wall about $3 \mathrm{~mm}$ thick containing several millilitres of clear, yellowish liquid (enterocystoma) (Fig. 6). A dense lymph node $0.5 \mathrm{~cm}$ in diameter was found in the base wall of the cyst. The histological structure of the walls of the cyst included a mucous membrane lined with ciliated epithelium, a fibro-muscular layer in the middle, and a serosa outside (Fig. 7). A lymph node accompanied by several lymph nodules existed in the wall of the cyst (Fig. 8).

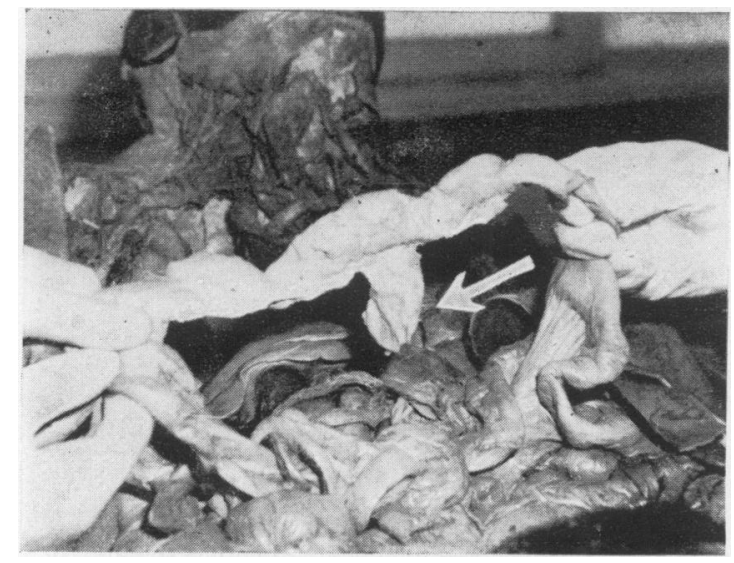

Fig. 6. (Case 3). Meckel's diverticulum with cystic appearance after dissection of the intestine.

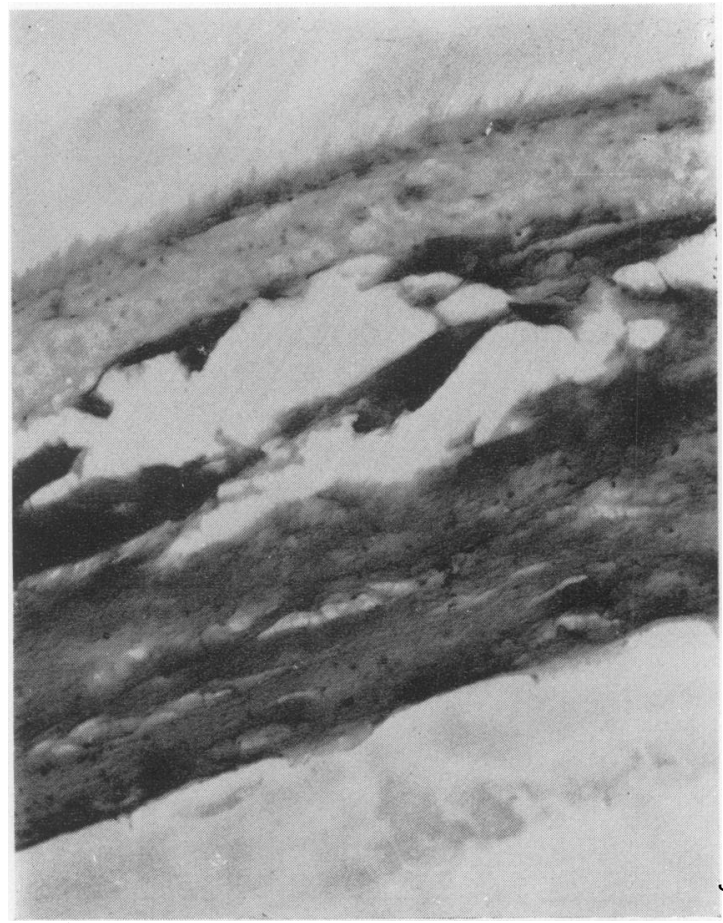

Fig. 7. (Case 3). High-power photomicrograph of ciliated epithelium of the wall of cystic diverticulum (at the top).

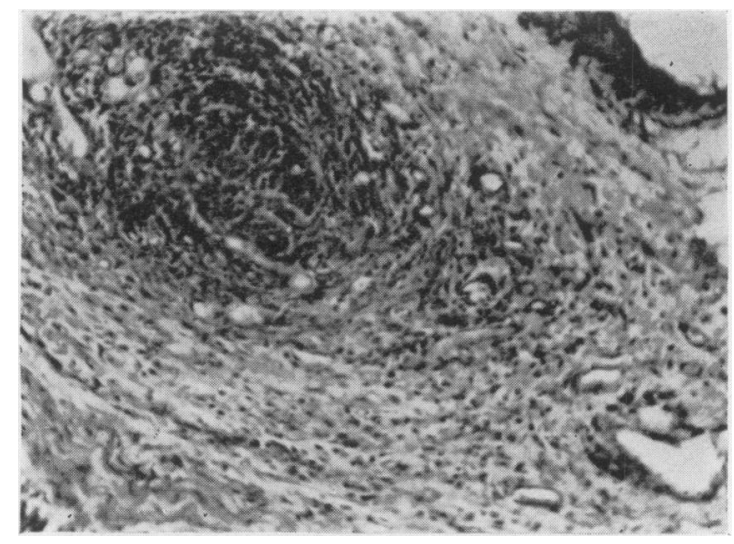

Fig. 8. (Case 3). Medium-power photomicrograph of the adjacent lymph node (ciliated epithelium of the cyst at the top right and lymph nodule with reaction centre at the lower left).

\section{Case 4}

The cadaver was that of a 55-year-old man. A Meckel's diverticulum, $3 \mathrm{~cm}$ long $\times 1 \mathrm{~cm}$ wide, was observed in the anterior surface of the ileum, $45 \mathrm{~cm}$ 


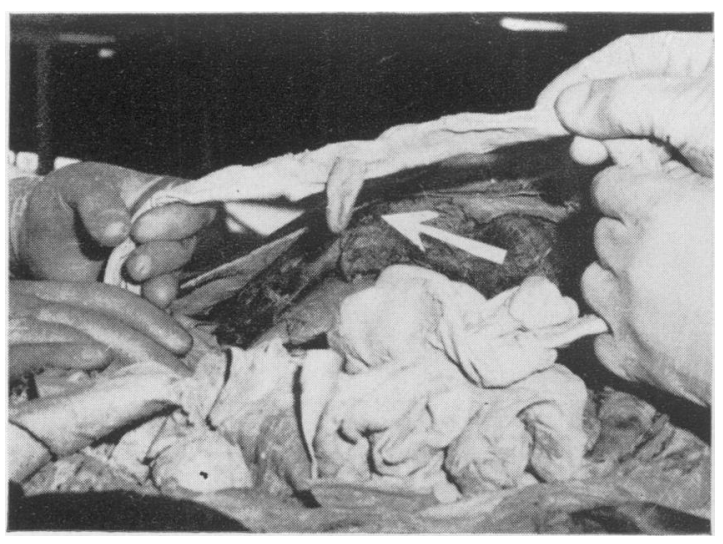

Fig. 9. (Case 4). Meckel's diverticulum resembling a glove finger after dissection of the intestine.

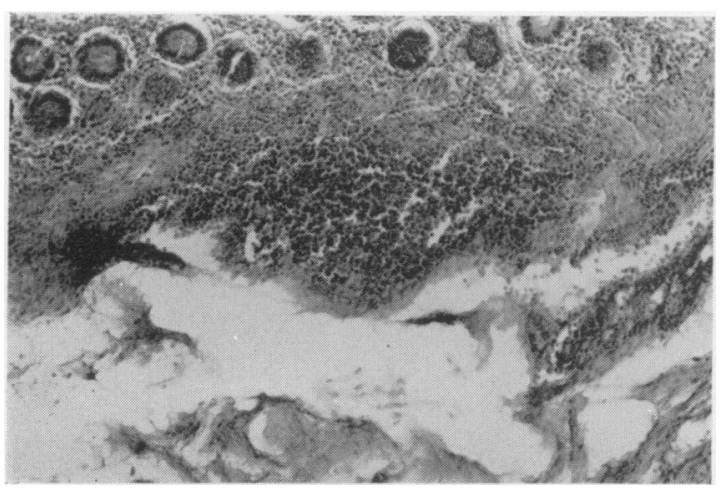

FIG. 10. (Case 4). Medium-power photomicrograph of Meckel's diverticulum with a Peyer's patch.

from the ileocaecal valve (Fig. 9). The diverticulum was connected to the intestine at the base and contained semi-fluid faeces. The serosa of the diverticulum was normal and its innermost coat resembled that of the small intestine. Its histological appearance was similar to the ileum but the crypts of Lieberkühn seemed relatively large (Figs. 10 and 11). No aberrant tissue was observed in serial sections.

\section{Case 5}

The cadaver was of a 60-year-old man. A Meckel's diverticulum, $2 \times 2.5 \mathrm{~cm}$, existed on the antimesenteric border of the small intestine at a distance of $79 \mathrm{~cm}$ from the ileocaecal valve (Fig. 12). Its entrance was connected to the intestine by a narrow opening of about $1 \mathrm{~cm}$ diameter. The valvulae conniventes, or Kerckring's folds, extended only to the entrance of the diverticulum and from there on the mucous surface of the diverticulum was smooth and without

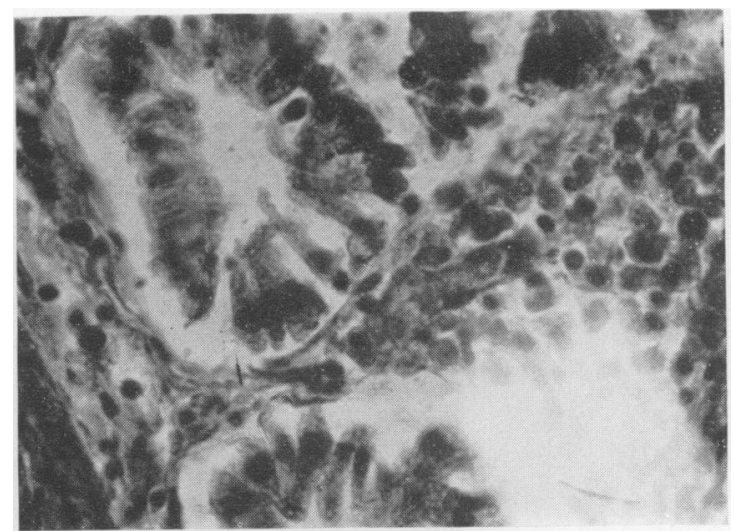

Fig. 11. (Case 4). High-power photomicrograph of Meckel's diverticulum in which the glands of Lieberkühn are expanded and active.

plicae circulares. In other words, the gross appearance of the diverticulum lacked Kerckring's folds as in the large intestine. The lack of plicae circulares in the diverticulum wall was confirmed on microscopy (Fig. 13). It would seem that this is the first reported case in which Meckel's diverticulum resembles the large intestine and lacks valvulae conniventes.

\section{Case 6}

The patient was a 30-year-old woman who had complained of abdominal pain, fever, rigors and vomiting. She had been treated with antibiotics and vitamins but died $\mathbf{4 0}$ days after being admitted to hospital with symptoms of intestinal occlusion. At autopsy a Meckel's diverticulum, $6 \mathrm{~cm}$ long, was found on the ileum about $20 \mathrm{~cm}$ from the ileocaecal valve which was inflamed and attached to the mesentery (Fig. 14). The inflammation extended to the tunica serosa of the bladder, and a vesico-ileal fistula was found (Fig. 15). Microscopically, diverticulitis accompanied by inflammatory reaction in the serous membrane was observed (Figs. 16 and 17).

\section{Discussion}

Persistence of a vestigial remnant of the omphalomesenteric, or vitelline, duct may give rise to a diverticulum in the ileum. This anomaly was first described and correctly interpreted in 1812 by Johann Friedrick Meckel, anatomist in Halle from 1781 to 1833 (Gurd, 1966; Martin, 1955). Meckel's diverticulum occurs on the antimesenteric border, like a glove finger, at a distance of $25-90 \mathrm{~cm}$ from the ileocaecal valve (Fig. 1). The length of the Meckel's diverticulum is usually $1-10 \mathrm{~cm}$ and its diameter $1-4$ $\mathrm{cm}$. The nutrient arteries and veins originate from the primitive omphalomesenteric or vitelline vessels. These vessels cross over the ileal wall and course 


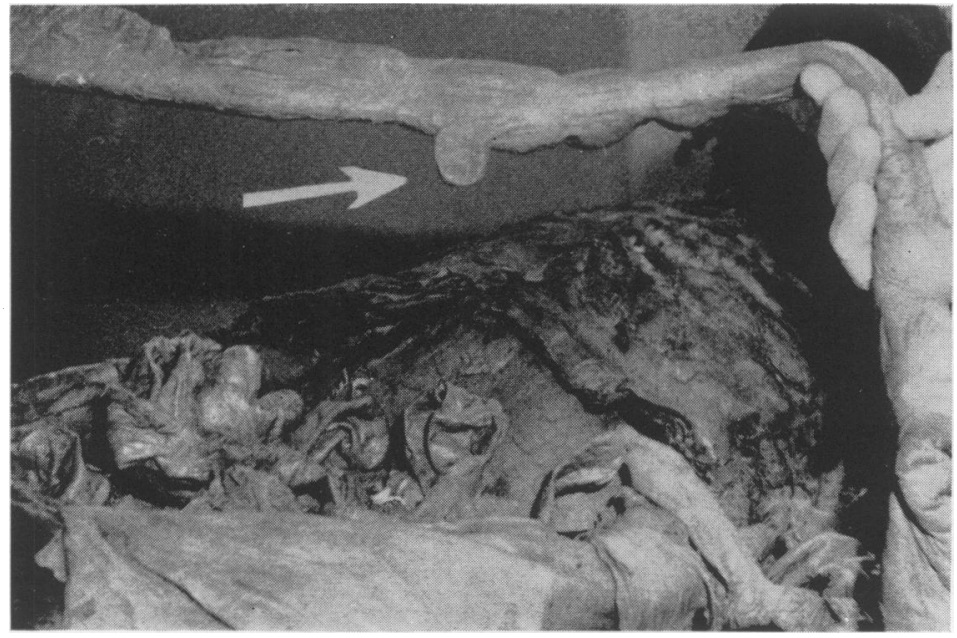

FIG. 12. (Case 5). Meckel's diverticulum is shown on the uplifted small intestine.

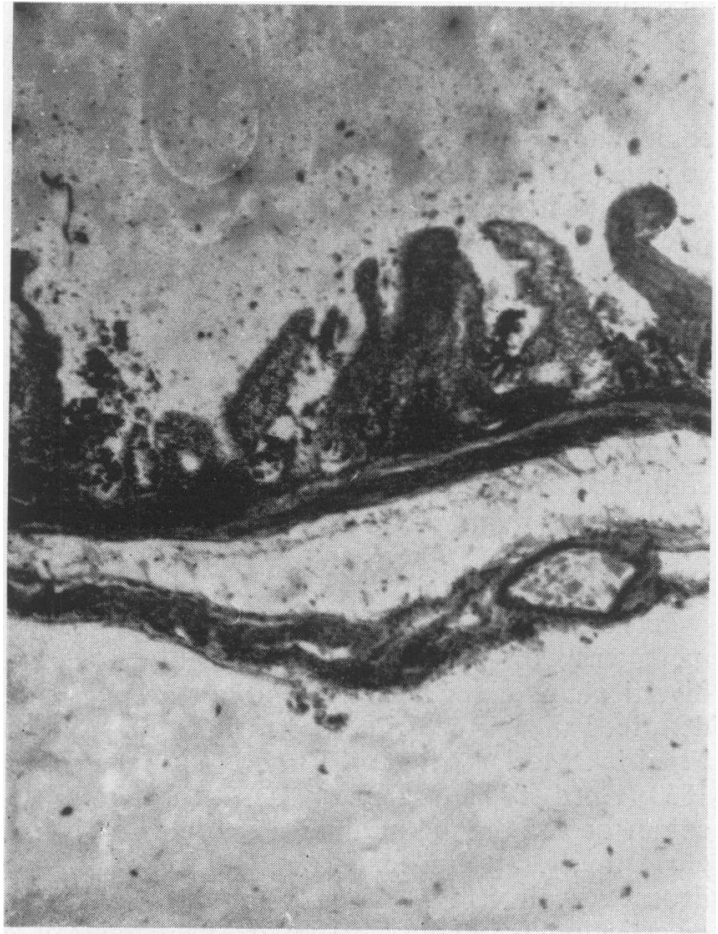

FIG. 13. (Case 5). Medium-power photomicrograph of Meckel's diverticulum with absence of the plicae circulares.

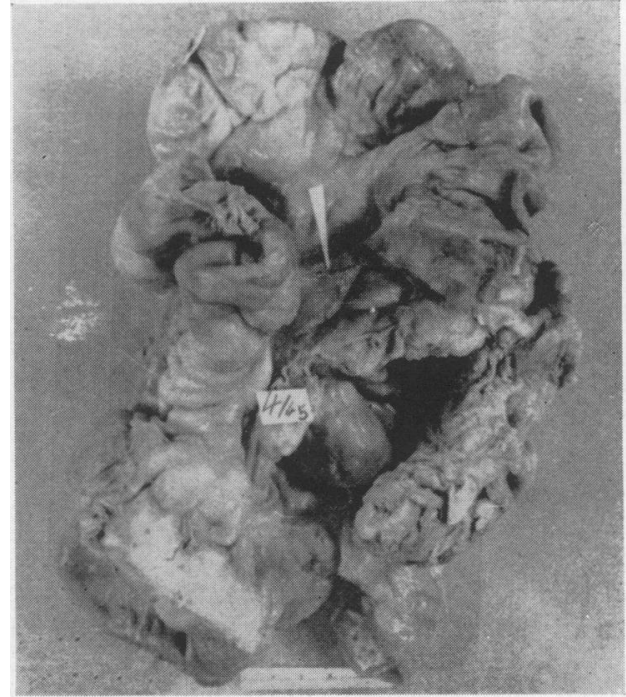

FIG. 14. (Case 6). Meckel's diverticulum causing a vesico-ileal fistula in a 30-year-old woman (arrow). 
subserously, or are confined in an accompanying mesentriolum, along the diverticulum to its tip (Fig. 1A) (Oppenheimer, 1962). The histological structure of the diverticulum is the same as that of the small intestine, namely, it is composed of mucous membrane, submucosa, muscular layers and tunica serosa from the inside out (Fig. 5) (Gurd,

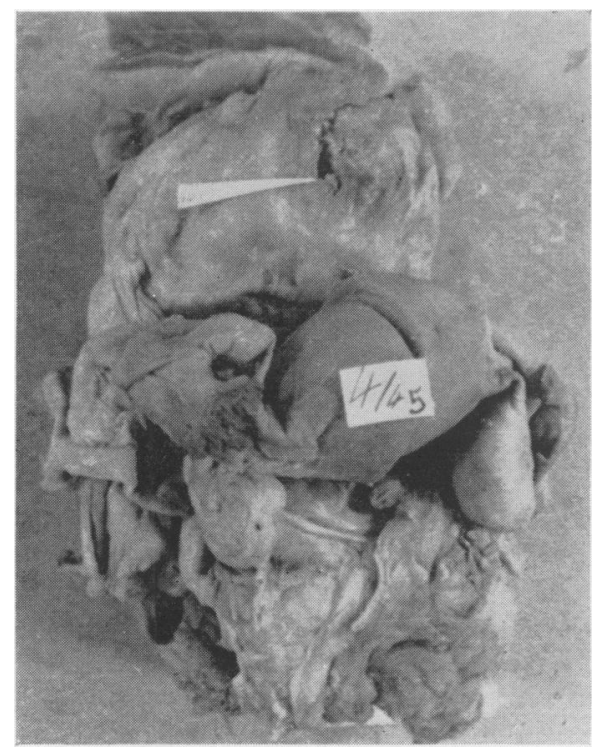

Fig. 15. (Case 6). The dissected diverticulum, showing the orifice of the fistula on the external surface of the bladder (arrow).
1966; Soderlund, 1959). In a large proportion of cases aberrant tissue is present. Ectopic gastric tissue has been found in $16 \%$ of all Meckel's diverticula, often accounting for haemorrhage (Hallendorf and Lovelace, 1947). Aberrant pancreatic tissue occurs in 3-4\%. Less commonly, duodenal or bile duct tissue is encountered (Gurd, 1966; Hallendorf and Lovelace, 1947).

Sometimes, the whole vitelline duct remains between the umbilicus and intestine as a tube-like structure, which causes an umbilical faecal fistula (Fig. 1в) (Oppenheimer, 1962). In some cases, the remnant of vitelline duct remains between the umbilicus and intestine in the form of a fibrous cord (Fig. 1c). This cord may cause strangulation of the intestinal loop (Hallbrook, 1970). The middle section may remain as a cyst, and the two ends form a fibrous cord (Fig. 1D). Such a case may subsequently cause enterocystoma as in Case 3 (Oppenheimer, 1962).

Most diverticula are asymptomatic and are incidental findings to abdominal exploration for other lesions, or at autopsy (Soderlund, 1959). The usual complications bringing the patient with Meckel's diverticulum to surgical attention are (a) inflammation, (b) haemorrhage,* (c) small bowel volvulus, strangulation or occlusion and (d) perforation (Altemeier and Bravant, 1963); Bacon and McGregor, 1961; Hallbrook, 1970). In all these situations the symptoms may appear in the right lower quadrant of the abdomen, in which case the signs are often indistinguishable from appendicitis or other cases of acute abdomen (Bacon and McGregor,

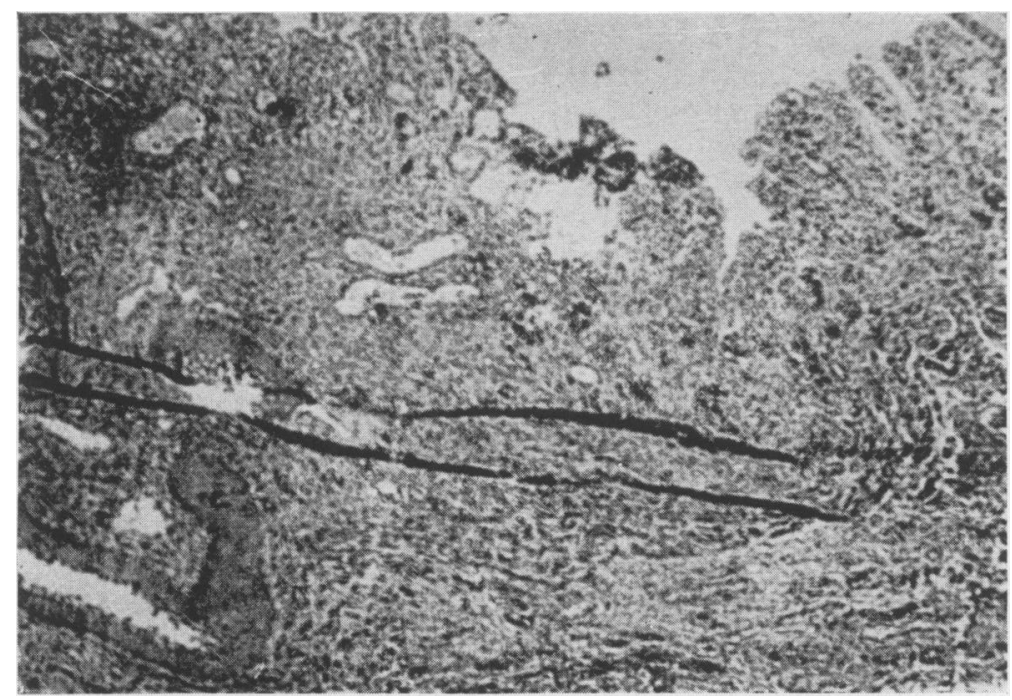

FIG. 16. (Case 6). Photomicrograph of serous membrane showing diverticulitis and inflammation. 


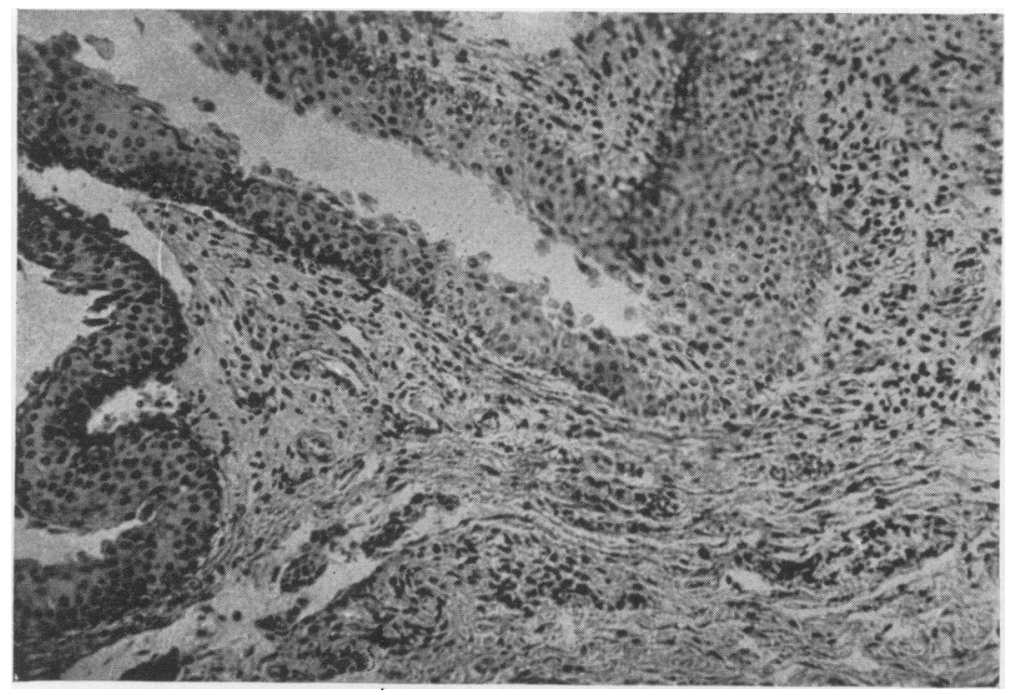

Fig. 17. (Case 6). Photomicrograph of serous membrane showing diverticulitis and inflammation.

1961 ; Soderlund, 1959; Thorek, 1952). Haemorrhage occurs more commonly in childhood and is usually brisk resulting from peptic ulceration secondary to heterotopic acid-secreting gastric mucosa in the diverticulum (Grossman, 1950; Kelley and Falk, 1960). This mucosa is nowadays easily diagnosed by means of a technetium $99 \mathrm{~m}$ scan (Harper, 1965; Lathrop, 1964). Meckel's diverticulum may be incarcerated in a hernia (Oppenheimer, 1962). Calculi (see footnote*) and foreign bodies such as fish bones sometimes become lodged within the diverticulum and lead to perforation (Kavlie and Marchioro, 1972). Polyps, leiomas, sarcomas, carcinomas and carcinoids have been reported as originating in Meckel's diverticulum (Jones, 1972).

Preoperative diagnosis of Meckel's diverticulum is seldom made. It would seem advisable, therefore, to pay attention to radiological studies (Kanter, 1968; Lerner, 1953).

(a) Barium meal followed by serial films of the abdomen is the most successful method of examination (James, 1952);

(b) useful radiological signs are the barium-filled diverticulum, the gas-filled diverticulum, and an opaque calculus lying within a bubble of gas;

\footnotetext{
* Radio-opaque calculi of Meckel's diverticulum that might cause bleeding should not be overlooked. The importance of this condition is recalled by the case of a 16-year-old boy referred with chronic anaemia since birth. The aetiology of the illness was finally demonstrated in the University of Washington Hospital to be a Meckel's diverticulum with chronic ulceration secondary to radio-opaque calculi (Kavlie and Marchioro, 1972).
}

(c) a ribbon-like opacity, representing the calculus $\overline{0}$ within the gas bubble, may be characteristic (James, $\varnothing$ 1952; Martin, 1955).

Preoperative diagnosis of Meckel's diverticulum is more important when haemorrhage occurs. The management of these patients is outlined as follows.

(a) Angiography for those with continued or recurrent bleeding (Kittredge, 1969; Reuter and Bookstein, 1968);

(b) arrest of bleeding by adrenalin perfusion through an arterial catheter (Rosch, 1971).

\section{References}

Altemeier, W.A. \& Bravant, L.R. (1963) The surgical significance of jejunal diverticulum. Archives of Surgery, 86, 732.

Bacon, H.E. \& McGregor, R.A. (1961) Diverticulitis and its surgical management. Surgery, 49, 676.

Grossman, J.W. (1950) Hemorrhage from a Meckel's diverticulum as a cause of melena in infancy. Report of a case in which the diverticulum was demonstrated roentgenologically. Radiology, 55, 240.

GuRD, H.H. (1966) A histological study of Meckel's diverticulum, with special reference to heterotopic tissues. Archives of Surgery, 32, 506.

HALLBOOK, T. (1970) Unusual complications in patients with Meckel's diverticulum. Acta chirurgica scandinavica, 136, 77.

Hallendorf, L.C. \& Lovelace, W.R. (1947) Aberrant gastric mucosa and pancreatic tissue in a bleeding Meckel's diverticulum. Mayo Clinic Proceedings, 22, 53.

HarPer, P.V. (1965) Technetium $99 \mathrm{~m}$ as a scanning agent. Radiology, 85, 101.

JAMES, T. (1952) Radiological visualization of a Meckel's diverticulum. British Journal of Radiology, 25, 221. 
JoNES, E.L. (1972) Argentaffin-cell tumour of Meckel's diverticulum, a report of 2 cases and review of the literature. British Journal of Surgery, 59, 213.

KANTER, I.E. (1968) Localization of bleeding point in chronic and acute gastrointestinal hemorrhage by means of selective visceral arteriography. American Journal of Roentgenology, 103, 386.

Kavlie, H. \& Marchioro, T. (1972) Calculi in a Meckel's diverticulum, a case of chronic anemia. Gastroenterology, 62, 1238.

Kelley, D.J. \& FalK, S. (1960) Hemorrhage from a solitary jejunal diverticulum. American Journal of Surgery, 100, 579.

KitTREDGE, R.D. (1969) The angiography of hemorrhage. American Journal of Roentgenology, 107, 181.

LATHROP, K.H. (1964) Diagnostic uses for technetium-99 m. Second Annual Oak Ridge Radioisotope Conference. April 19-22. Available as report TID-7689 from Commerce, Washington, 25, D.C.
LERNER, H.H. (1953) Meckel's diverticulum: A new roentgen diagnostic sign and case report. American Journal of Roentgenology, 69, 268.

Martin, E. (1955) Meckel's diverticulum with emphasis on the roentgen diagnosis. Radiology, 65, 572.

Oppenheimer, E. (1962) The Ciba Collection of Medical Illustration. A compilation of painting on the normal and pathologic anatomy of the digestive system. Colorpress: New York.

Reuter, S.R. \& Bookstein, J.J. (1968) Angiographic localization of gastrointestinal bleeding. Gastroenterology, $54,876$.

Rosch, J. (1971) Selective arterial infusion of vasoconstrictors in acute gastrointestinal bleeding. Radiology, 99, 27.

SODERLUND, S. (1959) Meckel's diverticulum-a clinical and histologic study. Acta chirugica scandinavica, Suppl. 248, 1. ThoreK, P.E. (1952) Acute abdominal emergencies. Postgraduate Medical Journal, 11, 139. 